\title{
Selective cytotoxicity of PAMAM G5 core-PAMAM G2.5 shell tecto-dendrimers on melanoma cells
}

This article was published in the following Dove Press journal:

International Journal of Nanomedicine

30 July 2012

Number of times this article has been viewed

\section{Priscila Schilrreff' \\ Cecilia Mundiña- \\ Weilenmann ${ }^{2}$ \\ Eder Lilia Romero' \\ Maria Jose Morilla'}

'Programa de Nanomedicinas, Universidad Nacional de Quilmes, Buenos Aires, Argentina; ${ }^{2}$ Centro de Investigaciones Cardiovasculares, Universidad Nacional de La Plata, La Plata, Argentina
Correspondence: Maria Jose Morilla Programa de Nanomedicinas, Departamento de Ciencia y Tecnología, Universidad Nacional de Quilmes, Roque Saenz Peña 352,

Bernal BI876 BXD, Argentina

Tel +54 II 43657100

Fax +54 II 43657 7 32

Email jmorilla@unq.edu.ar
Background: The controlled introduction of covalent linkages between dendrimer building blocks leads to polymers of higher architectural order known as tecto-dendrimers. Because of the few simple steps involved in their synthesis, tecto-dendrimers could expand the portfolio of structures beyond commercial dendrimers, due to the absence of synthetic drawbacks (large number of reaction steps, excessive monomer loading, and lengthy chromatographic separations) and structural constraints of high-generation dendrimers (reduction of good monodispersity and ideal dendritic construction due to de Gennes dense-packing phenomenon). However, the biomedical uses of tecto-dendrimers remain unexplored. In this work, after synthesizing saturated shell core-shell tecto-dendrimers using amine-terminated polyamidoamine (PAMAM) generation 5 (G5) as core and carboxyl-terminated PAMAM G2.5 as shell (G5G2.5 tecto-dendrimers), we surveyed for the first time the main features of their interaction with epithelial cells.

Methods: Structural characterization of G5G2.5 was performed by polyacrylamide gel electrophoresis, matrix-assisted laser desorption time-of-flight mass spectrometry, and microscopic techniques; their hydrodynamic size and Z-potential was also determined. Cellular uptake by human epidermal keratinocytes, colon adenocarcinoma, and epidermal melanoma (SK-Mel-28) cells was determined by flow cytometry. Cytotoxicity was determined by mitochondrial activity, lactate dehydrogenase release, glutathione depletion, and apoptosis/necrosis measurement.

Results: The resultant 60\%-67\% saturated shell, 87,000-dalton G5G2.5 (mean molecular weight) interacted with cells in a significantly different fashion in comparison to their building blocks and to its closest counterpart, PAMAM G6.5. After being actively taken up by epithelial cells, G5G2.5 caused cytotoxicity only on SK-Mel-28 cells, including depletion of intracellular glutathione and fast necrosis that was manifested above $5 \mu \mathrm{M}$ G5G2.5. It cannot be discounted that traces of $\mathrm{LiCl}$ within $\mathrm{G} 5 \mathrm{G} 2.5$ were involved in such deleterious effects.

Conclusion: These preliminary results suggest that at concentrations that do not damage healthy keratinocytes, G5G2.5 could display antimelanoma activity.

Keywords: core-shell tecto-dendrimers, SK-Mel-28 cells, oxidative stress

\section{Introduction}

Dendrimers were first described by Vögtle in $1978^{1}$ as highly branched macromolecules of unique structural properties, such as controlled size, shape, surface chemistry, flexibility, and near unit polydispersity. Polyamidoamine (PAMAM) dendrimers were the first water-soluble and essentially nonimmunogenic complete family to be synthesized, characterized, and commercialized. ${ }^{2}$ Toxicity of amine-terminated PAMAM dendrimers upon intravenous administration was formally screened in mice in $1996,{ }^{3}$ while the in vivo biodistribution of ${ }^{125}$ I-labelled PAMAM dendrimers in rats was determined in $2000 .{ }^{4}$ These and further studies ${ }^{5}$ of toxicity revealed similar 
trends after oral and intravenous administration. In general, the toxicity of cationic dendrimers increases with generation and dose, and is less pronounced than that of their neutral or anionic counterparts.

In the last five years, interest in biomedical applications of dendrimers has steadily grown, although the synthesis and particular aspects of their structure remain challenging. Classically, dendrimers are synthesized by sequential steps, by divergent ${ }^{2}$ or convergent ${ }^{6}$ techniques. However, beyond generation 5 (G5), the de Gennes dense-packing phenomenon reduces good monodispersity and precludes ideal dendritic construction. ${ }^{7,8}$ In this condition, the surface becomes crowded with terminal functional groups, and the addition of further generations often results in incomplete conjugation, leading to imperfect structures. Only a narrow window between G4 and G6 is available for drug hosting. Conversely, the inner pockets of larger PAMAM dendrimers become less accessible, or smaller dendrimers are widely open so as to retain guest molecules.

In this context, megamer or dendrimer clusters could be suitable alternatives to reduce the drawbacks associated with the synthesis and structure of dendrimers. These new types of polymers are synthesized by covalent cross-linking between dendritic units. ${ }^{9}$ Randomly assembled polymers can be prepared by bi- or tridimensional self-association, or by heat-induced covalent linkage. ${ }^{10}$ These highly polydisperse dendri-macrocycles, -catenanes or -clefts are nonuniform in size and shape, and are not of biomedical interest because of their structural irregularities. On the other hand, controlledstructure polymers, ${ }^{9,11,12}$ known as core-shell tecto-dendrimers, consist of a dendrimer core surrounded by a shell of lower-radii dendrimers. Depending on the synthesis method, partially filled or saturated shell structures can be obtained. The latter result from the combination of an amine-terminated core dendrimer with an excess of carboxylic acid-terminated, shell reagent dendrimer. ${ }^{11}$ The two charge-differentiated species are allowed to equilibrate and self-assemble into the electrostatically driven core-shell tecto-dendrimer architecture, followed by covalent fixing of these charge-neutralized dendrimer contacts with carbodiimide reagents.

Uppuluri et $\mathrm{al}^{11}$ showed that starting from PAMAM G5 as a core and a PAMAM G3 carboxylic acid terminated as shell, a high yield (ie, $90 \%$ ) of a new polymer with intermediate size between a G7 and a G8 dendrimer and 75\%-83\% saturation degree can be obtained in a single step. Noteworthy is that the addition of three generations to a G5 core by the divergent method would require six reaction steps. Additionally, the divergent synthesis of larger dendrimer requires excessive monomer loading and lengthy chromatographic separations. In this context, tecto-dendrimers could expand the portfolio of high molecular weight (MW) controlled structures without experiencing the de Gennes congestion, while at the same time retaining a suitable capacity for drug hosting.

In this work, using PAMAM G5 (MW: 28826, 128 amine surface groups) as core and PAMAM G2.5 (MW: 6265, 32 carboxylic surface groups) as shell, saturated shell core-shell G5G2.5 tecto-dendrimers were prepared (Figure 1) and their interaction with epithelial cells was surveyed. By considering that 15 is the maximum number of shell dendrimers that ideally park around the core, ${ }^{13}$ the theoretical MW of these tecto-dendrimers would be 122,000 daltons (Da). Besides, 240 carboxylic groups would be at the surface if we assume that half of the surface groups of each PAMAM G2.5 are exposed. It is expected therefore that these tecto-dendrimers possess a structure similar to a PAMAM G6.5 (MW: 106196) of 7-8 nm diameter. In comparison, the densely packed surface of G6.5 exposes 512 surface carboxylic groups.

The structural characterization of G5G2.5 was performed by polyacrylamide gel electrophoresis (PAGE), matrix-assisted laser desorption time-of-flight mass spectrometry (MALDI-TOF-MS) and microscopic techniques (transmission electron microscopy [TEM] and atomic force microscopy [AFM]). Besides, hydrodynamic size and Zeta potential was determined. Then, its cellular uptake by human epidermal keratinocytes ( $\mathrm{HaCaT}$ cells), epithelial colon adenocarcinoma cells (Caco-2 cells), and epidermal melanoma cells (SK-Mel-28 cells) was determined by flow cytometry. Finally, cytotoxicity was determined by measuring mitochondrial activity and lactate dehydrogenase release; additionally, glutathione depletion and apoptosis/ necrosis were measured.

\section{Materials and methods \\ Materials}

Ethylendiamine core PAMAM G5, G2.5, G3.5, G4.5, and G6.5 dendrimers were purchased from Sigma-Aldrich(StLouis, MO).
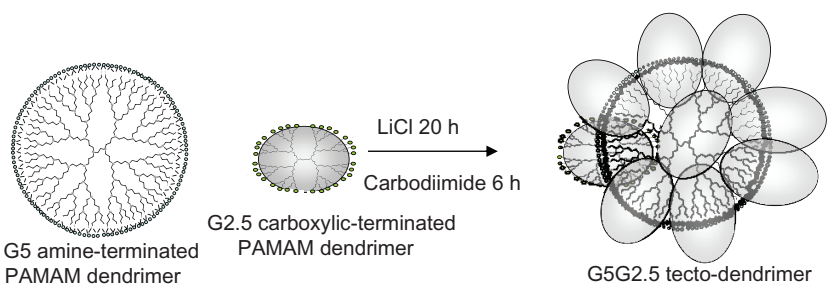

Figure I Schema of G5G2.5 tecto-dendrimer synthesis. Abbreviation: PAMAM, polyamidoamine. 
LiCl, 1-(3-dimethylaminopropyl)-3-ethylcarbodiimide hydrochloride (EDC), fluorescein isothiocyanate isomer I (FITC), 3-(4,5-dimethylthiazole-2-yl)-2,5-diphenyltetrazolium bromide) (MTT), high-retention cellulose dialysis tubing, 5,5'-dithio-bis(2-nitrobenzoic acid) (DTNB), glutathione reductase from baker's yeast (Saccharomyces cerevisiae), $\beta$-nicotinamide adenine dinucleotide $2^{\prime}$-phosphate reduced tetrasodium salt hydrate (NADPH), glutathione (GSH), propidium iodide, and Sephadex G-100 and G-25 were also purchased from Sigma-Aldrich. YO-PRO ${ }^{\circledR}-1$ was from Molecular Probes, Life Technologies (Eugene, OR). Modified Eagle's medium (MEM), sodium piruvate and L-glutamine were from Gibco, Life Technologies (Eugene, OR). Fetal bovine serum (FBS), trypsin-EDTA solution and antibiotic/ antimycotic solution were obtained from PAA Laboratories (Pasching, Austria). 4-(2-Hydroxyethyl)-1-piperazineethanesulfonic acid) (HEPES), tris-(hydroxymethyl) aminomethane (Tris) and $N, N^{\prime}$-methylene-bis-acrylamide were purchased from ICN Biomedicals (Aurora, OH). The other reagents were analytic grade from Anedra, Research AG (Buenos Aires, Argentina).

\section{Synthesis and characterization of G5G2.5}

\section{Synthesis and purification}

G5G2.5 tecto-dendrimers were synthesized as described by Uppuluri et al. ${ }^{11}$ Briefly, G5 in $23 \mathrm{mg} / \mathrm{mL} \mathrm{LiCl}$ solution and G2.5 in MilliQ water were mixed at a 1:30, G5:G2.5 molar ratio. The mixture was allowed to equilibrate for 20 hours at room temperature. Subsequently, the linking reagent EDC (34 mg) was added to the reaction mixture. After 6 hours, the mixture was exhaustively purified by dialysis using a 12,400-Da cutoff cellulose membrane against $500 \mathrm{~mL}$ of deionized water for 2 days, replaced five times with fresh water. After that, the sample was subjected to size-exclusion chromatography (Sephadex G-100), eluting with $10 \mathrm{mM}$ Tris-HCl pH 7.4 as mobile phase. Eluted fractions were collected, and samples of each fraction were run in $15 \%$ PAGE using TBE buffer (0.089 M Tris, 0.089 M boric acid, $2 \mathrm{mM}$ EDTA) $\mathrm{pH} 8.3$ at a constant voltage of $200 \mathrm{~V}$. Gels were stained with $0.1 \%$ Coomassie brillant blue R-250 in $20 \%(\mathrm{v} / \mathrm{v})$ methanol and $10 \%(\mathrm{v} / \mathrm{v})$ acetic acid and destained in the same solution (without the dye) to visualize bands. Fractions showing a band of lower electrophoretic mobility than G2.5 and similar to G6.5 were collected, lyophilized, and stored at $-20^{\circ} \mathrm{C}$.

Additionally, G5G2.5 was analyzed by gradient 8\%-30\% PAGE (0.375 M Tris-HCl pH 8.9 and $0.1 \%$ [w/v] SDS). Lyophilized G5G2.5 was solubilized with sample buffer
(31.25 mM Tris- $\mathrm{HCl}[\mathrm{pH} 6.8], 2 \%$ [w/v] SDS, 10\% [v/v] glycerol, 5\% [v/v] 2-mercaptoethanol, and $0.001 \%[\mathrm{w} / \mathrm{v}]$ bromophenol blue), and electrophoresis was performed using an electrode buffer of $0.025 \mathrm{M}$ Tris/0.192 glycine $\mathrm{pH} 8.3$ containing $0.1 \%(\mathrm{w} / \mathrm{v}) \mathrm{SDS}$ at constant voltage of $120 \mathrm{~V}$. After electrophoresis, gels were stained with Coomassie brillant blue R-250 as stated above.

\section{Molecular weight}

Molecular weight of G5G2.5 was estimated by MALDI-TOFMS according to Uppuluri et al. ${ }^{11}$ Briefly, $1 \mu \mathrm{L}$ of G5G2.5 ( $\sim 20 \mathrm{pmol})$ was mixed with matrix solution (50:50 v/v acetronitrile/water, containing $0.1 \% \mathrm{v} / \mathrm{v}$ trifluoracetic acid) and was spotted on the spectrometer plate, and the solvent was allowed to evaporate under ambient conditions. Afterwards, $1 \mu \mathrm{L}$ of matrix consisting of $10 \mathrm{mg} / \mathrm{mL} 2,5$-dihydroxybenzoic acid in matrix solution was spotted over the dry sample. Analysis was performed with a 4800 plus MALDI TOF/TOF mass spectrometer analyzer (AB Sciex, Framingham, MA) done in LANAIS-PRO (Laboratorio Nacional de Investigación y Servicios en Péptidos y Proteínas) operating in the linear positive mode. The value of the laser power was set at 5800 .

\section{Quantification}

The yield of each batch was determined by densitometry using G6.5 as standard. Increasing amounts of G6.5 ranging from 0.5 to $8 \mu \mathrm{g}$ and aliquots of G5G2.5 were loaded into $15 \%$ PAGE, run, and stained as stated before. Images were obtained and band intensity was determined by Image J software, (National Institutes of Health, Bethesda, MD). A plot of G6.5 mass in micrograms versus band intensity was fitted by linear regression.

\section{Transmission electron microscopy}

Aliquots of G5G2.5 were dropped on a standard carboncoated cooper TEM grid and then air-dried at room temperature overnight. TEM images were obtained with a JEM 1011 (Jeol, New York, NY) electron microscope at $80 \mathrm{kV}$. Images were processed with ImageJ software.

\section{Atomic force microscopy}

Aliquots of G5G2.5 were mixed with $1 \mathrm{M} \mathrm{MgCl}_{2}$, and dropped on freshly cleaved mica surfaces. After 5 minutes, the excess of sample was removed; the mica was washed and dried with $\mathrm{N}_{2}$. Samples were examined with a NanoScope III multimode AFM (Digital Instruments, Santa Barbara, CA) using tapping mode. Silicon probe with a spring constant of $40 \mathrm{~N} / \mathrm{m}$, resonant frequency of $300 \mathrm{kHz}$, and a tip 
radius smaller than $10 \mathrm{~nm}$ were used for tapping scans (MPP-11100; Bruker, Camarillo, CA). Image analysis was performed with WSxM (Nanotec, Madrid, Spain) software.

\section{Size and zeta potential}

Size and zeta potential of polymers (G2.5, G5, G6.5, and G5G2.5) in Hank's balanced salt solution (HBSS) and culture medium were determined by dynamic light scattering and phase analysis light scattering, respectively, using a Nanosizer (ZEN 3600; Malvern Instruments, Malvern, UK). Lyophilized G5G2.5 and dry aliquots of dendrimers were solubilized with HBSS or MEM prefiltered across $0.02 \mu \mathrm{m}$ by mechanical agitation.

\section{Lithium determination}

Lithium was determined by ion-selective electrodes using an EasyLyte $\mathrm{Na} / \mathrm{K} / \mathrm{Cl} / \mathrm{Li}$ analyzer (Medica, Newtonville, MA) and by inductively coupled plasma mass spectroscopy (ICP-MS) using an ELAN DRC-e system (PerkinElmer, Waltham, MA) equipped with a dynamic reaction cell for interference corrections.

\section{Cell cultures}

SK-Mel-28 cells, human melanoma cells (ATCC, HTB-72), were obtained from Asociación Banco Argentino de Células. $\mathrm{HaCaT}$ cells, immortalized human nontumorigenic keratinocites, were kindly provided by Dr Edgardo Salvatierra, Instituto Leloir, Argentina. Caco-2 cells, human colonic adenocarcinoma cells, were kindly donated by Dr Osvaldo Zabal, INTA Castelar, Argentina.

Cells were routinely culture in MEM supplemented with $10 \%(\mathrm{v} / \mathrm{v}) \mathrm{FBS}, 1 \%(\mathrm{v} / \mathrm{v})$ antibiotic/antimycotic solution and $2 \mathrm{mM}$ glutamine, at $37^{\circ} \mathrm{C}$ in $5 \% \mathrm{CO}_{2}$ and $95 \%$ humidity. Caco- 2 cells were cultured in the same conditions, except that the culture medium was also supplemented with $1 \mathrm{mM}$ sodium piruvate.

\section{Kinetics of cellular uptake}

Kinetics of uptake of G2.5, G6.5, and G5G2.5 by HaCaT, Caco-2, and SK-Mel-28 cells were determined by flow cytometry. To that aim, polymers were labeled with FITC, as described by Kitchens et al. ${ }^{14}$ Briefly, polymer solutions were treated with a threefold molar excess of EDC and incubated for 30 minutes. Then, three times molar excess of ethylene diamine was added to the mixture and incubated for 4 hours. FITC $(5 \mathrm{mg} / \mathrm{mL})$ was dissolved in acetone and slowly added to this solution at a 1:20 molar ratio, followed by incubation at room temperature for 24 hours in the dark.
The FITC-labeled polymers were then separated from free FITC by size-exclusion chromatography on a Sephadex-G25 column. The presence of polymers in the void volume was confirmed by $15 \%$ PAGE, as stated before. The absence of free FITC in the conjugates was verified by thin-layer chromatography, using chloroform and methanol (1:1) as solvents..$^{15}$ The extent of FITC conjugation was determined by measuring the absorbance of labeled polymers at $492 \mathrm{~nm}$ using a UV-visible spectrophotometer (UV-1603; Shimadzu, Kyoto, Japan). Number of moles of FITC conjugated per polymer was calculated using FITC calibration curve in Tris-HCl buffer.

Cells were seeded at a density of $3.0 \times 10^{5}$ cells/well in 6-well plates and grown to reach $70 \%-80 \%$ of confluence. Subsequently, the medium was replaced with $1.5 \mathrm{~mL}$ of fresh medium containing around $7 \mu \mathrm{M}$ of each FITC-labeled polymer, and the cells were incubated for $0.5,1,3$, and 5 hours at $37^{\circ} \mathrm{C}$. After each incubation period, the medium was removed; the cells were washed with phosphate-buffered saline (PBS, $\mathrm{pH}$ 7.4), and harvested by trypsinization. The fluorescence of the noninternalized polymers attached to the plasma membrane was quenched by 10-minute incubation with $0.2 \% \mathrm{v} / \mathrm{v}$ trypan blue in PBS. After washing with PBS, a total of 10,000 cells were analyzed by flow cytometry (FACSCalibur; Becton Dickinson, San Jose, CA). Data were analyzed using WinMDI 2.9 (Microsoft, Redmond, WA) software.

Additionally, cells grown on 6-well plates as previously stated were preincubated for 1 hour at $4^{\circ} \mathrm{C}$ prior to addition of the FITC-labeled polymers. The cells were then incubated for 5 hours at $4^{\circ} \mathrm{C}$ and processed for flow cytometry.

\section{Cytotoxicity}

Cell viability upon treatment with polymers was measured by MTT assay and lactate dehydrogenase (LDH) leakage in culture supernatants. Cells were seeded at a density of $4 \times 10^{4}$ cells/well in 96-well plates and allowed to attach overnight. The medium was then replaced with fresh medium with 5\% FBS containing increasing concentrations from 15 to $150 \mu \mathrm{M}$ of G2.5 G6.5 from 50 to $150 \mu \mathrm{M}$ or from 5 to $50 \mu \mathrm{M}$ of G5G2.5 and cells were incubated at $37^{\circ} \mathrm{C}$ in a $5 \% \mathrm{CO}_{2}$ humidified incubator. After 24 hours, the supernatants were transferred to fresh tubes, centrifuged at $250 \times \mathrm{g}$ for $4 \mathrm{~min}-$ utes, and the LDH content was measured using a CytoTox LDH kit (Promega, Madison, WI). Percent of LDH leakage was expressed relative to treatment with Triton X-100. Cells attached to plates were processed for MTT assay. A $0.45-\mathrm{mg} /$ mL MTT solution was added and incubated for 3 hours. The 
solution was then removed, the insoluble formazan crystals were dissolved with dimethylsulfoxide, and absorbance was measured at $570 \mathrm{~nm}$ using a microplate reader. Cell viability was expressed as a percentage of the viability of cells grown in medium. The same was performed to assess toxicity of $\mathrm{LiCl}$ at 50 and $500 \mathrm{mM}$ on Sk-Mel-28 cells.

\section{Determination of intracellular glutathione} Determination of Sk-Mel-28 intracellular GSH upon polymer treatment was based on a modification of the Tietze recycling method, ${ }^{16}$ where the amount of measured GSH represents the sum of reduced and oxidized glutathione in the sample.

Cells were seeded at a density of $2 \times 10^{5}$ cells/well in 24-well plates and allowed to attach overnight. The medium was then replaced with fresh medium with 10\% FBS containing increasing concentrations from 15 to $150 \mu \mathrm{M}$ of $\mathrm{G} 2.5 \mathrm{G} 6.5$ from 50 to $150 \mu \mathrm{M}$ or from 5 to $50 \mu \mathrm{M}$ of G5G2.5 and cells were incubated at $37^{\circ} \mathrm{C}$ in a $5 \% \mathrm{CO}_{2}$ humidified incubator. After 12 hours of exposure, the media were removed and cells were washed with PBS and collected into Eppendorf tubes by trypsin treatment. Then trypsin was inactivated, cells were washed twice with PBS by centrifugation $\left(1000 \times \mathrm{g}\right.$ for 5 minutes at $\left.4^{\circ} \mathrm{C}\right)$ and suspended in $1 \mathrm{~mL}$ of ice-cold extraction buffer $(0.1 \%$ Triton$\mathrm{X}$ and $0.6 \%$ sulfosalicylic acid in $0.1 \mathrm{M}$ potassium phosphate buffer with $5 \mathrm{mM}$ EDTA disodium salt, pH 7.5 [KPE]). Cells were lysed by sonication in icy water for 2-3 minutes and vortexing every 30 seconds, followed by freeze at $-80^{\circ} \mathrm{C}$ and defrosted on ice twice; finally, cellular debris was removed by centrifugation $\left(3000 \times \mathrm{g}\right.$ for 4 minutes at $\left.4^{\circ} \mathrm{C}\right)$. Aliquots $(20 \mu \mathrm{L})$ of supernatants were transferred to 96 -well plates for GSH determination. Then $120 \mu \mathrm{L}$ of reaction mixture $(4.2 \mathrm{mM}$ DTNB and $1.0 \mathrm{U} / \mathrm{mL}$ GSH reductase in KPE) was added to each well, and after 30 seconds for conversion of GSSG to GSH, $60 \mu \mathrm{L}$ of $0.24-\mathrm{mM} \beta-\mathrm{NADPH}$ in KPE was added. The rate of 2-nitro-5-thiobenzoic acid (TNB) formation ( $\triangle \mathrm{Abs} /$ minute) was calculated by immediate readings of the absorbance at $412 \mathrm{~nm}$ taken every 30 seconds for 2 minutes in a microplate reader (tc MRX; Dynex Technologies, Chantilly, VA). The rate of TNB formation was linearly proportional to the total concentration of GSH in the sample. A regression curve was generated using GSH as standard from 50 to $0.8 \mu \mathrm{M}$. Total GSH concentration in the sample was expressed as $\mathrm{nM} \mathrm{GSH} / \mu \mathrm{g}$ protein, for which total proteins in each cellular pellet was measured by Bradford assay ${ }^{17}$ using bovine serum albumin as standard.

\section{Apoptosis/necrosis assay}

Apoptotic and necrotic Sk-Mel-28 cells upon polymer treatment were identified by a double staining with $\mathrm{YO}-\mathrm{PRO}^{\circledR}-1$ and propidium iodide (PI) by flow cytometry. This assay detects changes in cell membrane permeability with YO$\mathrm{PRO}^{\circledR}-1$ dye, a green-fluorescent nucleic acid stain that is permeant to apoptotic cells but not to live cells. Necrotic cells are labeled with red fluorescent PI.

Cells were seeded at a density of $3 \times 10^{5}$ cells/well in 6-well plates and allowed to grow for 24 hours. The medium was then replaced with fresh medium with $10 \%$ FBS containing $50 \mu \mathrm{M}$ G6.5 or 5 and $10 \mu \mathrm{M} \mathrm{G} 5 \mathrm{G} 2.5$, and cells were incubated at $37^{\circ} \mathrm{C}$ in a 5\% $\mathrm{CO}_{2}$ humidified incubator. After 3 and 7 hours of exposure, the media were removed and cells were washed with PBS and collected into Eppendorf tubes by trypsin treatment. Then trypsin was inactivated, cells were washed twice with PBS by centrifugation $\left(1000 \times \mathrm{g}\right.$ for 5 minutes at $\left.4^{\circ} \mathrm{C}\right)$, and cell density was adjusted to $\sim 1 \times 10^{6}$ cells $/ \mathrm{mL}$ in PBS. The cells were incubated with $1 \mu \mathrm{L}$ of YO-PRO ${ }^{\circledR}-1100 \mu \mathrm{M}$ for 15 minutes and $1 \mu \mathrm{L}$ of PI $0.01 \mathrm{mg} / \mathrm{mL}$ for 2 minutes. The stained cells were analyzed within 1 hour by flow cytometry (FACSCalibur), using $488 \mathrm{~nm}$ excitation with green fluorescence emission for YO-PRO ${ }^{\circledR}-1$ (530 nm FL1) and red fluorescence emission for PI ( $>575 \mathrm{~nm}, \mathrm{FL} 3)$. A total of 10,000 cells were analyzed, and data were analyzed using WinMDI 2.9 software.

\section{Statistical analysis}

Statistical analyses were performed by one-way ANOVA, followed by Dunnett test using Prisma 4.00 software (Graphpad Software, San Diego, CA). Significance levels are shown in figure legends.

\section{Results and discussion Synthesis and characterization of G5G2.5}

Gradient PAGE analysis performed at normal polarity of a sample representative of a minimum of nine batches showed that G5G2.5 run as a diffuse band of lower relative mobility than the band of G6.5 (MW 106196 Da) (Figure 2A). G5G2.5 was accompanied by residual free G2.5 shell dendrimers. A second PAGE performed at reversed polarity showed the absence of residual G5 core. The yield of each synthetic batch was determined by PAGE densitometry employing G6.5 as standard, resulting a mean mass of $3 \pm 0.7 \mathrm{mg}$ (Figure 2C).

The MW of G5G2.5 was estimated by MALDI-TOF-MS. The spectra of at least three independent batches indicated a molecular weight peak at $\sim 87,000 \mathrm{Da}$ (Figure 3), with an MW distribution between 75,000 and 96,000 Da. The peak at $\sim 43000 \mathrm{Da}$ can be assigned to a doubly charged ion of G5G2.5. Similar spectra were obtained by Uppuluri et a ${ }^{11}$ employing PAMAM G5 as core and PAMAM G3-carboxylic acid terminated as shell. 

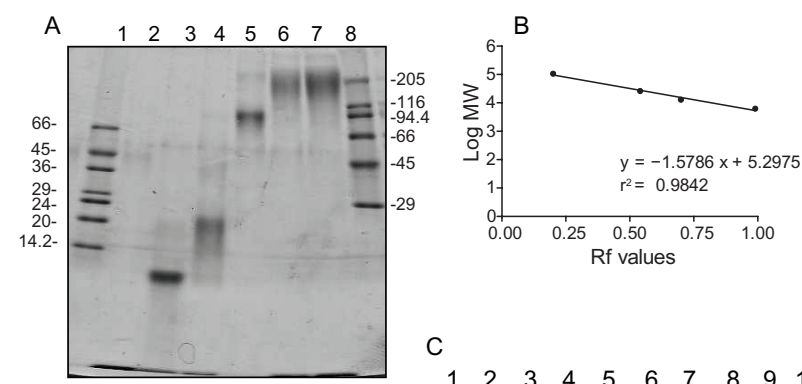

$\begin{array}{llllllllll}1 & 2 & 3 & 4 & 5 & 6 & 7 & 8 & 9 & 10\end{array}$

Figure 2 (A) Gradient (8\%-30\%) PAGE analysis of G5G2.5 (lanes 6 and 7) compared with PAMAM G2.5, G3.5, G4.5 and G6.5, lanes 2 to 5, respectively. Low and high molecular mass markers are represented in lanes I and 8, respectively and indicated in kilodaltons $(\mathrm{kDa})$. (B) Linear regression analysis of the log of $\mathrm{MW}$ of dendrimers used as markers (G2.5-G6.5) versus relative mobility (Rf) was used to determine G5G2.5 MW. (C) Mass of G5G2.5 (lanes I and 2) was determined by PAGE densitometry employing the mass of G6.5 (8-0.5 $\mu \mathrm{g}$, lanes 3-10, respectively) as standard. Each G6.5 band contained a dimer band.

Abbreviations: PAGE, polyacrylamide gel electrophoresis; PAMAM, polyamidoamine; $\mathrm{MW}$, molecular weight.

Typical TEM (A) and AFM (B) images of G5G2.5 are shown in Figure 4. TEM images showed fractal structured aggregates and spherical structures with an average diameter of $7.20 \pm 2.06 \mathrm{~nm}$ (calculated by measuring more than 80 particles in random TEM fields; Figure 4A inset). Previous studies revealed the existence of fractal structures similar to those found by us, when an excess of anionic PAMAM G3.5 is combined with cationic PAMAM G4 in the presence of LiCl. ${ }^{18}$ AFM images, on the other hand, showed ellipsoidal structures of $17.9 \pm 4.9 \mathrm{~nm}$ mean diameter and $1.1 \pm 0.2 \mathrm{~nm}$ height (calculated by measuring nearly 20 molecules per field on five independent fields). It was previously observed that dendrimer diameters measured by AFM are much larger than those predicted by theoretical calculations, a fact that suggests that dendrimers "spread out" and flatten on the mica surface forming a semispherical dome. ${ }^{19}$ The molecular volume (V) of G5G2.5 was therefore calculated employing the following equation: $\mathrm{V}=1 / 6 \pi h\left(h^{2}+3 / 4 d^{2}\right),{ }^{12}$ where $h$ is the measured height and $d$ is the measured diameter of each G5G2.5. Assuming that G5G2.5 possesses the same density of $1.230 \mathrm{~g} / \mathrm{cm}^{3}$ as a dendrimer of close $\mathrm{MW},{ }^{20}$ the MW of G5G2.5 as estimated by this independent method was 106,000 Da with standard deviation of 36,000.

The hydrodynamic size and Z-potential of G5G2.5, G2.5, G5, and G6.5 in different media are shown in Table 1. Hydrodynamic diameter of G5G2.5 was around $11 \mathrm{~nm}$ both in HBSS and in culture media (MEM). This size was larger than that of its precursors $\mathrm{G} 2.5$ and G5 and in the order of that of G6.5. On the other hand, the Z-potential of G5G2.5, G2.5, and G6.5 in HBSS was slightly negative ( -4 to $-9 \mathrm{mV}$ ), while as expected that of G5 dendrimer was positive $(5.4 \mathrm{mV})$. The Z-potential of G5G2.5 and G6.5 decreased in culture media to -16.6 and $-13.5 \mathrm{mV}$, respectively, while that of G2.5 remained slightly negative $(-3.3 \mathrm{mV})$.

Gradient PAGE analysis was also used to estimate the MW of G5G2.5, by extrapolating the relative mobility of G5G2.5 in a plot of log MW dendrimers (G2.5-G6.5) versus relative mobility (Figure 2B). However, by this technique, the estimated MW of G5G2.5 was $\sim 130000 \mathrm{Da}$, nearly $50 \%$ higher than the value determined by MALDI-TOF-MS. This can be attributed to the fact that PAGE is not an accurate technique for determining MW of polymers other than globular proteins. For instance, highly branched PAMAM dendrimers with nearly spherical shapes display more compact structures and migrate faster than globular protein standards with the same molecular mass. ${ }^{21}$ In our gradient PAGE, the MW of dendrimers was underestimated (eg, 97,000, 20,600, and 11,000 Da, instead of 106,000, 26,258, and 12,900 Da for G6.5 G4.5, and G3.5, respectively). On the contrary, the open shell made of G2.5 ellipsoids around G5G2.5 would constitute a less compact structure of less congested surface than that of G6.5. This could be the reason for the low relative mobility of G5G2.5 as compared to G6.5, thus resulting in an overestimation of its MW. Although tecto-dendrimers are expected to be relatively

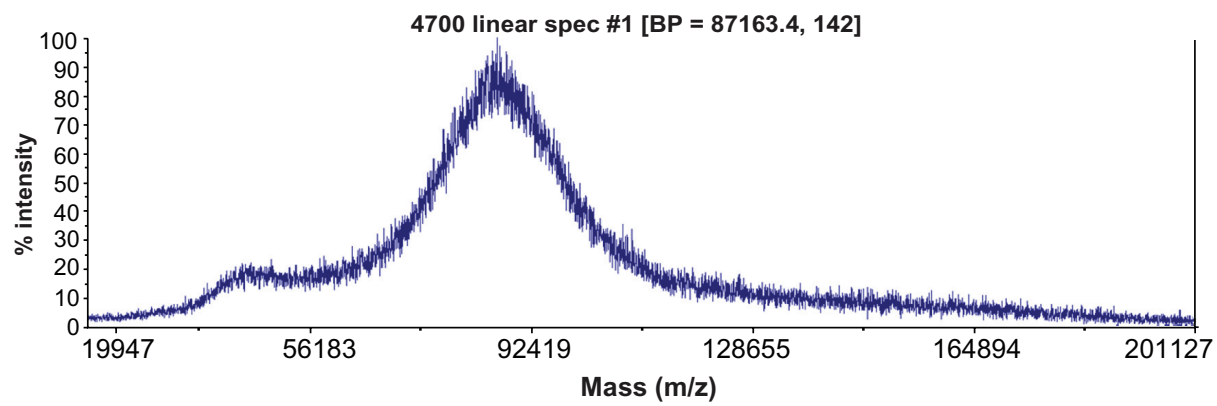

Figure 3 Typical matrix-assisted laser desorption time-of-flight mass spectrum of G5G2.5 tecto-dendrimers. Abbreviation: BP, base peak. 

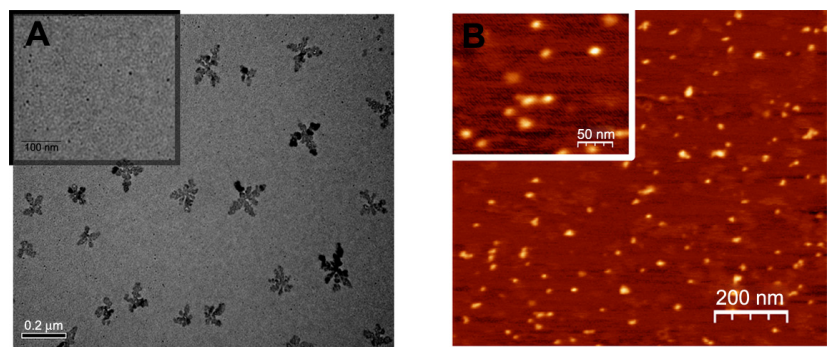

Figure 4 Transmission electron microscopy (A) and atomic force microscopy (B) of G5G2.5.

monodisperse, less so than their dendrimers building blocks, ${ }^{9}$ a factor contributing to their structural heterogeneity could arise from the different parking positions of the ellipsoidal G2.5 around the G5 core. Linkages along the long axis would lead to a maximum number of dendrimers in the shell than if the linkage is made along the short axis.

Taken together, these results showed that G5G2.5 had a negatively charged surface, the same as carboxylic halfgeneration dendrimers, an electrophoretic mobility lower than that of G6.5, a hydrodynamic size larger than that of its precursors and close to that of G6.5, as well as a mean MW of 87,000 Da. Considering that each G5G2.5 consists of a single G5 core dendrimer, a mean of 9-10 G2.5 dendrimer shell would be surrounding the central core, which corresponds to a saturation level of $60 \%-67 \%$. On the bases of this information, we screened the effects caused by G5G2.5 at 5, 15, and $50 \mu \mathrm{M}$ on different epithelial cells in comparison to those caused by G2.5 at 15, 50, and $150 \mu \mathrm{M}$ and G6.5 at 15 and $50 \mu \mathrm{M}$.

\section{Cell uptake kinetics}

First, the cellular uptake of FITC-labeled G2.5, G6.5, and G5G2.5 was followed for 5 hours. The quantification of the

Table I Size and Z-potential of G2.5, G5, G6.5, and G5G2.5 in different media

\begin{tabular}{|c|c|c|c|c|}
\hline & \multicolumn{2}{|c|}{ Hydrodynamic size (nm) } & \multicolumn{2}{|c|}{ Z-potential (mV) } \\
\hline & HBSS & MEM & HBSS & MEM \\
\hline G5G2.5 & $\begin{array}{l}10.5 \pm 1.9 \\
\text { (Pdl: } 0.729)\end{array}$ & $\begin{array}{c}9.8 \pm 1.6 \\
\text { (PdI: } 0.764)\end{array}$ & $-4.0 \pm 0.7$ & $-16.6 \pm 4.5$ \\
\hline $\mathrm{G} 2.5$ & $\begin{array}{l}\text { I. } 60 \pm 0.9 \\
\text { (Pdl: } 0.627)\end{array}$ & $\begin{array}{l}5.53 \pm 0.6 \\
\text { (Pdl: } 0.606)\end{array}$ & $-5.7 \pm 1.4$ & $-3.3 \pm 0.7$ \\
\hline G5 & $\begin{array}{l}7.26 \pm 0.87 \\
\text { (Pdl: } 0.689)\end{array}$ & $\begin{array}{l}6.72 \pm 0.25 \\
\text { (Pdl: } 0.440)\end{array}$ & $4.5 \pm 0.5$ & $-2.5 \pm 2.3$ \\
\hline G6.5 & $\begin{array}{l}\text { II } .5 \pm 0.7 \\
\text { (Pdl: } 0.558)\end{array}$ & $\begin{array}{l}12.9 \pm 0.4 \\
\text { (Pdl: } 0.246)\end{array}$ & $-9.0 \pm 1.2$ & $-13.5 \pm 0.7$ \\
\hline
\end{tabular}

Notes: Hydrodynamic size and Z-potential are expressed as mean \pm standard deviation of three independent measurements.

Abbreviations: HBSS, Hank's balanced salt solution; MEM, modified Eagle's medium; Pdl, polydispersity. amount of FITC per polymer conjugate showed 0.4 FITC molecules per G2.5 molecule, 3.5 FITC molecules per G6.5 molecule, and 22 FITC molecules per G5G2.5 molecule. The amount of FITC per polymer was used to normalize its fluorescence intensity, in order to establish a comparison between the cell uptakes of conjugates.

As shown in Figure $5 \mathrm{~A}-\mathrm{C}$, the uptake of polymers at $37^{\circ} \mathrm{C}$ by the three cell types followed a linear kinetics. A comparison of the curve slopes from normalized fluorescence intensity versus time plots showed that in general, polymers were taken up by Sk-Mel-28 cells at rates much faster than by $\mathrm{HaCaT}$ and Caco-2 cells (Table 2). The uptake extent was $\mathrm{G} 2.5>>\mathrm{G} 6.5 \sim \mathrm{G} 5 \mathrm{G} 2.5$ by the three cell types, except that the uptake of G6.5 by HaCaT cells was nearly fourfold higher than that of $\mathrm{G} 5 \mathrm{G} 2.5$. The uptake extent at $4^{\circ} \mathrm{C}$ was reduced from $15 \%$ to $5 \%$ the value at $37^{\circ} \mathrm{C}$ in all cells, suggesting the involvement of an energy-dependent process.

\section{Cytotoxicity}

The effect of G2.5G5 on the viability of the three cell types was determined by measuring the mitochondrial activity by the MTT assay and the cell membrane damage by leakage of cytosolic LDH.

The absent or low cytotoxicity of carboxylic halfgeneration dendrimers has previously been reported by several authors., ${ }^{3,422}$ PAMAM G2.5, G3.5, and G4.5 have been shown to be toxic only at high concentration of $10 \mathrm{mM}$ on Caco-2 cells, ${ }^{23-25}$ whereas G6.5 was not cytotoxic up to $100 \mu \mathrm{M}$ on human ovarian carcinoma cell line A2780. ${ }^{26}$ Similarly, we found that the viability of $\mathrm{HaCaT}$, Caco-2, and Sk-Mel-28 cells as determined by MTT (Figure 6A and C) and by LDH (Figure 5, B and D) assays were not modified after 24 hours of incubation with G2.5 or G6.5 up to 150 and $50 \mu \mathrm{M}$, respectively. However, while the viability of Caco- 2 and $\mathrm{HaCaT}$ cells was not affected by G2.5G5, that of Sk-Mel-28 cells was decreased in a dose-dependent fashion (Figure 6E and F). Indeed, doses of 5, 15, and $50 \mu \mathrm{M} \mathrm{G} 2.5 \mathrm{G} 5$ reduced to $60 \%, 30 \%$, and $20 \%$ the cell viability by MTT and released $50 \%, 90 \%$, and $100 \%$ of the cell LDH into the extracellular fluid, respectively. A linear correlation was observed between the toxicity determined by MTT and LDH release. The inhibitory concentration (IC50) of G5G2.5 on Sk-Mel-28 cells derived from the dose-response curve was $7.5 \mu \mathrm{M}$. The lack of toxicity of G5G2.5 on Caco-2 and HaCaT cells was not a surprising result, but their selective toxicity on Sk-Mel-28 cells was.

On the other hand, $\mathrm{LiCl}$ at $5-20 \mathrm{mM}$ is known to inhibit the growth of human melanoma cells and also to induce a 


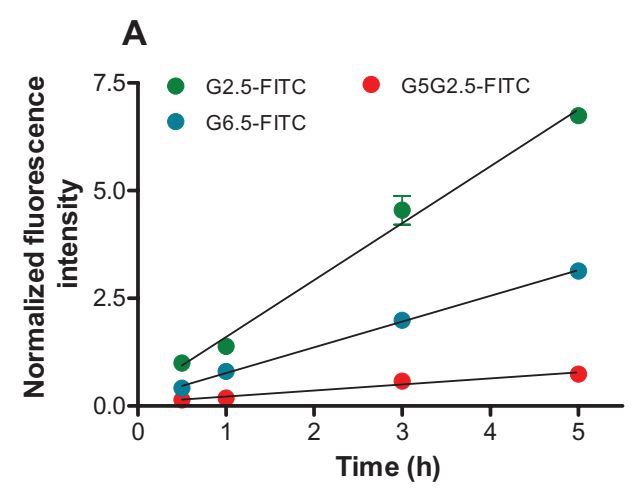

\section{B}

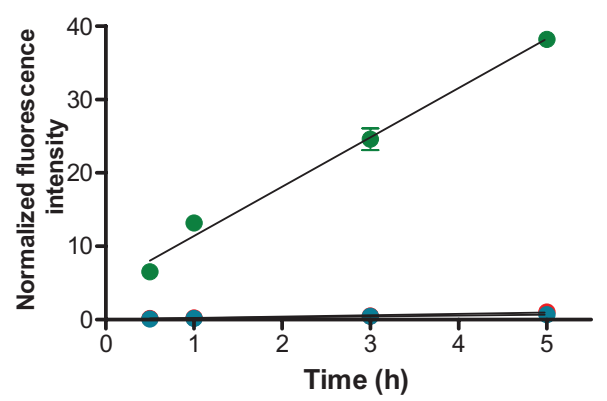

C

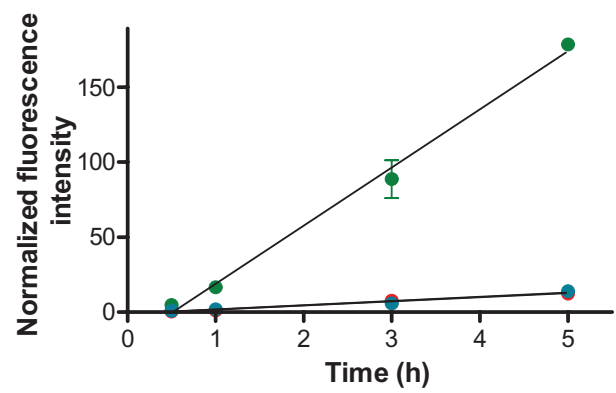

Figure 5 Uptake of G2.5-fluorescein isothiocyanate (FITC), G6.5-FITC, and G5G2.5-FITC by HaCaT (A), Caco-2 (B), and SK-Mel-28 cells (C) at $37^{\circ} \mathrm{C}$ as a function of time.

growth delay of inoculated melanoma tumours in syngeneic mice. ${ }^{27}$ Moreover, it was recently shown that in different cell types (osteosarcoma, colon carcinoma, fibroblasts, HeLa, and $\mathrm{HaCaT}$ cells), $\mathrm{LiCl}$ induces the release of TNF- $\alpha$ to the extracellular space, where it binds to cells' death receptors and induces apoptosis at an IC50 between 10 and $60 \mathrm{mM}{ }^{28}$ Here, the synthesis of G5G2.5 was carried out at $330 \mathrm{mM}$. The presence of $\mathrm{LiCl}$ was required in order to avoid bimodal or trimodal product mass distributions due to clustering of the amine-terminated core reagent into various domain sizes instead of monodispersed products. ${ }^{11}$ With the aim of determining if the selective toxicity of G5G2.5 could be due to residual $\mathrm{LiCl}$, the amount of lithium in purified G5G2.5 was quantified employing ion-selective electrode and also by ICP-MS. By the first method, the absence of lithum was recorded, meaning that the lithium amount was below the

Table 2 Linear-fit parameters of polymer-cell uptake versus time

\begin{tabular}{|c|c|c|c|c|c|c|}
\hline \multirow{2}{*}{$\begin{array}{l}\text { Polymerl } \\
\text { cell type }\end{array}$} & \multicolumn{2}{|l|}{ G2.5 } & \multicolumn{2}{|l|}{ G6.5 } & \multicolumn{2}{|c|}{ G5G2.5 } \\
\hline & Slope & $r^{2}$ & Slope & $r^{2}$ & Slope & $r^{2}$ \\
\hline $\mathrm{HaCaT}$ & 1.321 & 0.9858 & 0.5981 & 0.9982 & 0.1409 & 0.9559 \\
\hline Caco-2 & 6.725 & 0.9850 & 0.1273 & 0.9932 & 0.1897 & 0.9564 \\
\hline SK-Mel-28 & 38.80 & 0.9856 & 2.804 & 0.9524 & 2.773 & 0.9895 \\
\hline
\end{tabular}

detection limits $(0.5 \mathrm{mM})$ or that lithium was included within the polymer pockets, resulting in it being inaccessible to the electrode. The second method detected lithium at $8.5 \mu \mathrm{g} / \mathrm{L}$ $(1.21 \mu \mathrm{M})$ after the sample was vaporized, broken down into atoms, and ionized by plasma at extreme temperature. Data extrapolated from a known mass amount of G5G2.5 revealed that nearly $1.13 \mu \mathrm{mol} \mathrm{LiCl} \mathrm{remained} \mathrm{associated} \mathrm{per} 1 \mu \mathrm{mol}$ G5G2.5. Finally, we determined that after 24-hour incubation with 500 and $50 \mathrm{mM} \mathrm{LiCl}, 90 \%$ and $12 \%$ of LDH was released from Sk-Mel-28 cells, respectively (Figure 6F, inset). Hence, while $50 \mathrm{mM} \mathrm{LiCl}$ was a nontoxic concentration, the amount of lithium associated with $50 \mu \mathrm{M}$ G5G2.5 that was strongly cytotoxic was $56.5 \mu \mathrm{M}, 1000$-fold lower. We could speculate therefore that the toxicity of G5G2.5 on SK-Mel-28 cells was not due to the LiCl. However, it cannot be discounted that the uptake of G5G2.5 could increase the cytotoxicity of lithium traces that remained associated with the polymer structure if the intracellular pathway followed by lithium was modified.

\section{Intracellular GSH determination}

Reactive oxygen species (ROS), including hydrogen peroxide $\left(\mathrm{H}_{2} \mathrm{O}_{2}\right)$, superoxide $\left(\mathrm{O}_{2}^{-}\right)$and hydroxyl radical $(\mathrm{HO})$ are short-lived molecules capable of causing oxidative damage 
A

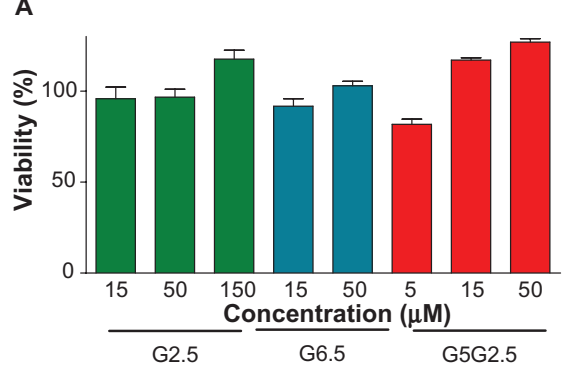

C

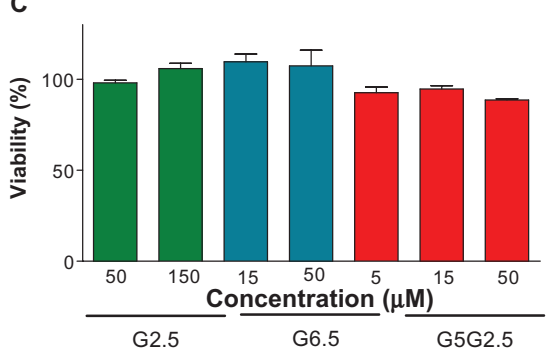

E

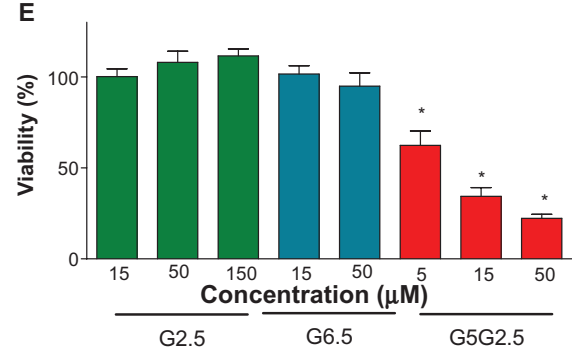

B

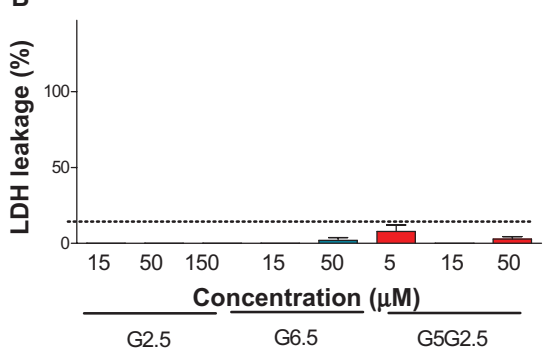

D
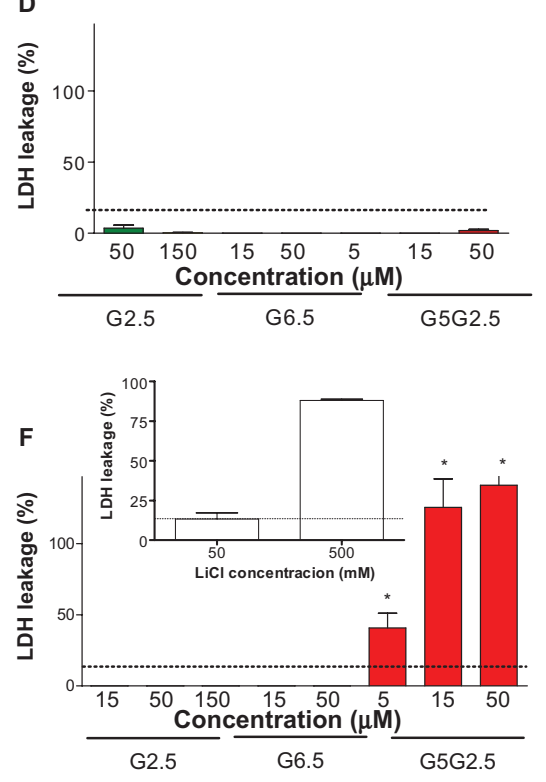

Figure 6 Cytotoxicity of G2.5, G6.5, and G5G2.5 on HaCaT cells (A and B), Caco-2 cells (C and D), and SK-Mel-28 cells (E and F), determined by 3-(4,5-dimethylthiazole2-yl)-2,5-diphenyltetrazolium bromide (A, $\mathbf{C}$ and $\mathbf{E}$ ) and lactate dehydrogenase (LDH) leakage (B, $\mathbf{D}$ and $\mathbf{E})$.

Notes: Bars represent means \pm standard deviations $(n=6)$. $* P<0.01$.

to DNA, lipids, and proteins. Oxidative stress is a state of redox disequilibrium in which ROS production overwhelms the antioxidant defense capacity of the cell, thereby leading to adverse biological consequences. Among different ROS scavengers, GSH, GSH $S$-transferase, and glutathione GSH reductase, the GSH-dependent system is of great importance. ${ }^{29}$ The depletion of intracellular levels of GSH as a consequence of ROS generation, proinflammatory effects and cell apoptosis are well-known mechanisms of cytotoxicity mediated by nanoparticles. ${ }^{30,31}$

Recent studies have shown that PAMAM G4, G5, and G6 dendrimers induce oxidative stress by producing ROS $^{32}$ and therefore a cytotoxic response in $\mathrm{HaCaT}$ cells, primary adenocarcinoma cells (SW480 cells), and murine macrophages (J774 cells). ${ }^{33,34}$ The cationic surface amine groups play a direct role in the production of ROS. Cationic nanoparticles have been shown to localize in mitochondria, generating ROS and producing a cytotoxic response via the mitochondrial injury pathway. ${ }^{32,35,36}$ However, anionic dendrimers have not been found as responsible for the generation of ROS. In view of the unexpected deleterious effects caused by G5G2.5 on Sk-Mel-28 cells, we investigated if such cytotoxicity could be related to a depletion of intracellular GSH. To that end,

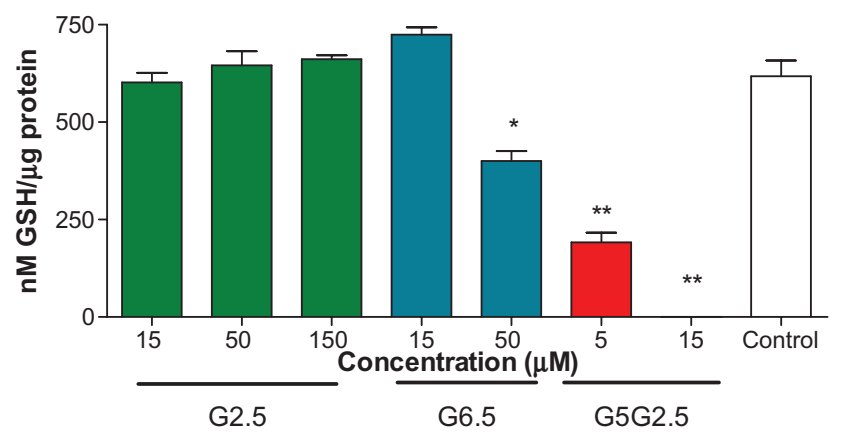

Figure 7 Intracellular glutathione (GSH) measurement on Sk-Mel-28 cells I $2 \mathrm{~h}$ after G2.5, G6.5, and G5G2.5 treatments.

Notes: Bars represent means \pm standard deviations $(\mathrm{n}=6)$. $* P<0.05 ; * * p<0.01$. 

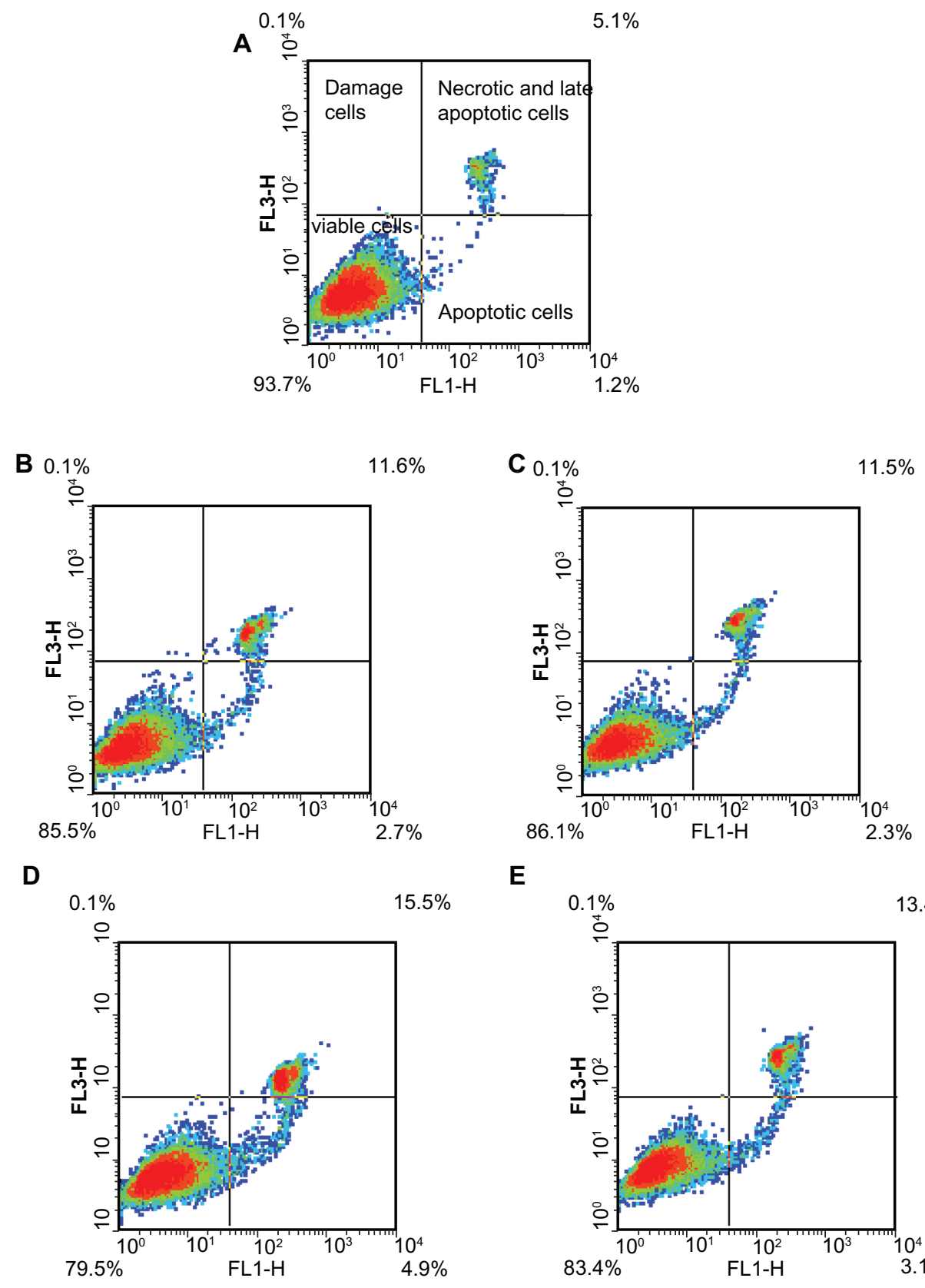

F

E
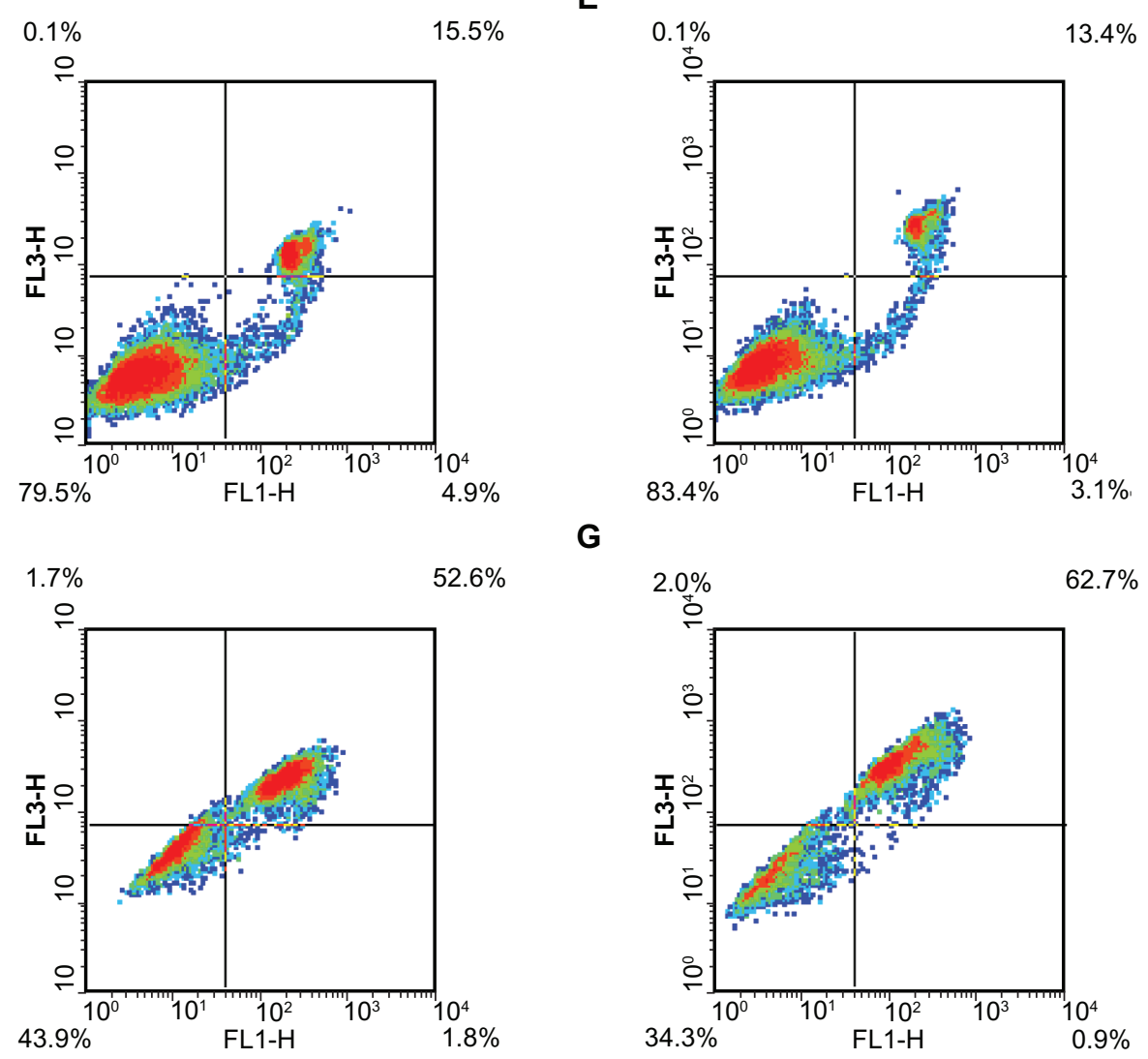

G

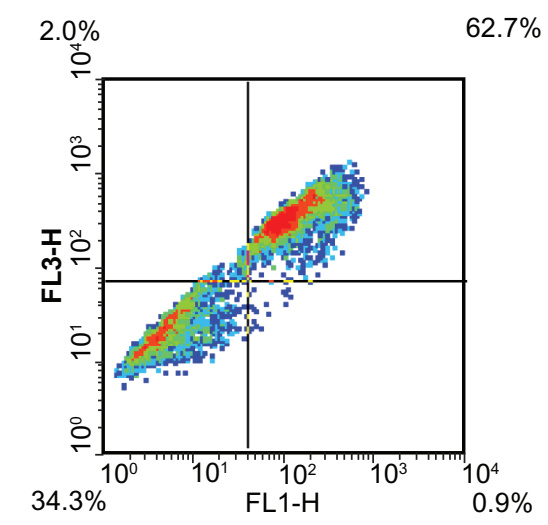

Figure 8 Density plot diagrams of apoptosis/necrosis assay on SK-Mel-28 cells. (A) Control cells; (B and C) cells incubated with $50 \mu$ M G6.5 for 3 and 7 hours, respectively; (D and E) cells incubated with $5 \mu$ M G5G2.5, for 3 and 7 hours, respectively; (F and $\mathbf{G}$ ) cells incubated with I5 $\mu$ M G5G2.5 for 3 and 7 hours, respectively. 
Sk-Mel-28 cells were incubated for 12 hours with G5G2.5 at 5 and $15 \mu \mathrm{M}$ (two concentrations below and above the IC50, respectively). Controls with $15 \mu \mathrm{M} \mathrm{G} 2.5$ and G6.5 showed that the intracellular GSH level was not modified; a slight decrease of GSH level (25\%) was produced by $50 \mu \mathrm{M}$ G6.5. However, G5G2.5 at 5 and $15 \mu \mathrm{M}$ caused a significant (75\% and 100\%, respectively) decrease of intracellular GSH (Figure 7). These results led us to conclude that after 12 hours and even at concentrations below the IC50, the G5G2.5 was responsible for consuming the intracellular GSH. Melanoma cells have a poor ability to cope with the oxidative stress, ${ }^{37-39}$ a fact that may be attributed to constitutive abnormalities in their melanosomes. The natural intracellular GSH level of SK-Mel-28 cells is $\sim 80-100 \mathrm{nmol} / \mathrm{mg}$ protein, whereas that of $\mathrm{HaCaT}$ cells is $7300 \mathrm{nmol} / \mathrm{mg}$ protein. ${ }^{40}$ Therefore, probably the low basal level of intracellular GSH in SK-Mel-28 cells was a reason for their susceptibility to GSH depletion caused by G5G2.5.

\section{Apoptosis assay}

Mitochondria are both the source and target of ROS, and they are responsible for producing cellular energy. Apoptotic activation of mitochondria leads to a disturbance of the mitochondrial membrane potential (MMP), permeability transition, ROS generation, and the release of apoptotic proteins. ${ }^{41}$ Therefore, we finally determined whether the depletion of intracellular GSH was related to the triggering of apoptosis. The results showed that $50 \mu \mathrm{M} \mathrm{G6.5} \mathrm{did} \mathrm{not} \mathrm{induce}$ significant cell death, either upon 3 or 7 hours of incubation (Figure $8 \mathrm{~B}$ and $\mathrm{C}$ ). On the other hand, after 3 and 7 hours of incubation with $15 \mu \mathrm{M}$ G5G2.5, only $46 \%$ and $37 \%$ cells remained viable, respectively, whereas the remaining 51\% and $57 \%$ were in late apoptosis or necrosis (Figure $8 \mathrm{~F}$ and $\mathrm{G}$ ). In these conditions, there were no cells observed in early apoptosis. When G5G2.5 concentration was reduced below IC50 $(5 \mu \mathrm{M})$, nearly $83 \%$ of cells remained viable, $12 \%$ of cells were in late apoptosis or necrosis, and only $5 \%$ of cells were in early apoptosis (Figure 8D and E). The percentage of early apoptotic cells was similar to the obtained after irradiating Sk-Mel-28 cells for 30 minutes with UV light.

The cells were rapidly damaged, but the extent or nature of the damage did not progress between 3 and 7 hours. Moreover, even after 24 hours (MTT assay), the cell-death percentage was similar to that after 3 hours. At $5 \mu \mathrm{M}$ G5G2.5, a small number of cells entered apoptosis, meanwhile $15 \mu \mathrm{M}$ G5G2.5 induced substantial necrosis or late apoptosis that did not progress during 24 hours.

Therefore, the nature and extent of the damage induced by G5G2.5 at $5 \mu \mathrm{M}$ on SK-Mel-28 cells was different to that caused at $15 \mu \mathrm{M}$. We observed that higher concentration but not longer incubations increased the percentage of nonviable cells, with a poor contribution of early apoptotic component (the current method impaired distinguishing between late apoptosis and necrosis).

\section{Conclusion}

Although the synthesis of tecto-dendrimers was reported more than 10 years ago, their effect on mammal cell has not been reported yet. The PAMAM G5 core and 60\%-67\% PAMAM G2.5 shell saturation tecto-dendrimers synthesized here behaved in a significantly different way to their building blocks, but also to their G6.5 counterpart. We found that G5G2.5 was avidly uptaken by SK-Mel-28 cells, a melanoma cell line that also showed a higher uptake of anionic dendrimers than the other epithelial (HaCaT) and enterocytic (Caco-2) cells. We also found that in spite of the purification process, small amounts of lithium remained associated within G5G2.5. Although the main finding of this work was that G5G2.5 caused a selective and concentration-dependent cytotoxicity on SK-Mel-28 cells, it cannot be discounted that such toxicity was related to changes in the intracellular pathway followed by lithium within G5G2.5, with respect to free lithium. Our data also showed that G5G2.5 cytotoxicity was related to a rapid depletion of intracellular levels of GSH. Although more detailed research is needed to reveal the role of structural architecture of tecto-dendrimers on its selective toxicity, these results suggest that G5G2.5 display an important antimelanoma activity.

\section{Acknowledgments}

This work was supported by the Secretaria de Investigaciones, Universidad Nacional de Quilmes, EULANEST project Nanoskin and CONICET. The authors are grateful to Dr T Creczynski-Pasa from Departamento de Ciências Farmacêuticas, Universidade Federal de Santa Catarina, Brazil, PROSUL project CNPq, for TEM and AFM analysis. PS has a fellowship from Consejo Nacional de Investigaciones Científicas y Técnicas, Argentina (CONICET). MJM, CMW, and ELR are members of the Carrera del Investigador Científico del CONICET.

\section{Dislosure}

The authors report no conflicts of interest in this work.

\section{References}

1. Bhuleier E, Wehner W, Vögtle F. "Cascade"- and "nonskid-chain-like" syntheses of molecular cavity topologies. Synthesis. 1978;2:155-158. 
2. Tomalia DA, Baker H, Dewald J, et al. A new class of polymers: starburst-dendritic macromolecules. Polym J. 1985;17:117-132.

3. Roberts JC, Bhalgat MK, Zera RT. Preliminary biological evaluation of polyamidoamine (PAMAM) Starburst dendrimers. J Biomed Mater Res. 1996;30(1):53-65.

4. Malik N, Wiwattanapatapee R, Klopsch R, et al. Dendrimers: relationship between structure and biocompatibility in vitro, and preliminary studies on the biodistribution of 125I-labelled polyamidoamine dendrimers in vivo. J Control Release. 2000;65(1-2):133-148.

5. Greish K, Thiagarajan G, Herd H, et al. Size and surface charge significantly influence the toxicity of silica and dendritic nanoparticles. Nanotoxicology. Epub July 28, 2011.

6. Hawker CJ, Fréchet JMJ. Preparation of polymers with controlled molecular architecture. A new convergent approach to dendritic macromolecules. J Am Chem Soc. 1990;112:7638-7647.

7. Lothian-Tomalia MK, Hedstrand DM, Tomalia DA, Padias AB, Hall HK Jr. A contemporary survey of covalent connectivity and complexity. The divergent synthesis of poly(thioether) dendrimers. Amplified, genealogically directed synthesis leading to the de Gennes dense packed state. Tetrahedron. 1997;53:15495-15513.

8. de Gennes PG, Hervet HJ. Statistics of "starburst" polymers. Europhys Lett. 1983;44:351-360.

9. Tomalia DA, Uppuluri S, Swanson DR, Li J. Dendrimers as reactive modules for the synthesis of new structure-controlled, higher-complexity megamers. Pure Appl Chem. 2000;72:2343-2358.

10. Tomalia DA, Hedstrand DM, Wilson LR. Dendritic polymers. In: Mark HF, Bikales N, Overberger CG, Menges G, editors. Encylopedia of Polymer Science and Engineering. New York: Wiley; 1990:46-92.

11. Uppuluri S, Piehler LT, Li J, Swanson DR, Hagnauer GL, Tomalia DA. Core-shell tecto(dendrimers): I. Synthesis and characterization of saturated shell models. Adv Mater. 2000;12:796-800.

12. Li J, Swanson DR, Qin D, et al. Characterizations of core-shell tecto(dendrimer) molecules by tapping mode atomic force microscopy. Langmuir. 1999;15:7347-7350.

13. Tomalia DA, Brothers HM 2nd, Piehler LT, Durst HD, Swanson DR. Partial shell-filled core-shell tecto(dendrimers): a strategy to surface differentiated nano-clefts and cusps. Proc Natl Acad Sci U SA. 2002;99(8):5081-5087.

14. Kitchens KM, Kolhatkar RB, Swaan PW, Eddington NW, Ghandehari H. Transport of poly(amidoamine) dendrimers across caco-2 cell monolayers: influence of size, charge and fluorescent labeling. Pharm Res. 2006;23:2818-2826.

15. Jevprasesphant R, Penny J, Attwood D, McKeown NB, D'Emanuele A. Engineering of dendrimer surfaces to enhance transepithelial transport and reduce cytotoxicity. Pharm Res. 2003;20(10):1543-1550.

16. Rahman I, Kode A, Biswas SK. Assay for quantitative determination of glutathione and glutathione disulfide levels using enzymatic recycling method. Nat Protoc. 2006;1(6):3159-3165.

17. Bradford MM. A rapid and sensitive method for the quantitation of microgram quantities of protein utilizing the principle of protein-dye binding. Anal Biochem. 1976;72:248-254.

18. Jasmine MA, Prasad E. Fractal growth of PAMAM dendrimer aggregates and its impact on the intrinsic emission properties. J Phys Chem B. 2010;114:7735-7742.

19. Li J, Piehler LT, Qin D, Baker JR Jr, Tomalia DA. Visualization and characterization of poly(amidoamine) dendrimers by atomic force microscopy. Langmuir. 2000;16:5613-5616.

20. Betley TA, Banaszak Holl MM, Orr BG, Swanson DR, Tomalia DA, Baker JJR. Tapping mode atomic force microscopy investigation of poly(amidoamine) dendrimers: effects of substrate and $\mathrm{pH}$ on dendrimer deformation. Langmuir. 2001;17:2768-2773.

21. Shi X, Patri AK, Lesniak W, et al. Analysis of poly(amidoamine)succinamic acid dendrimers by slab-gel electrophoresis and capillary zone electrophoresis. Electrophoresis. 2005;26:2960-2967.
22. Bhadra D, Bhadra S, Jain S, Jain NK. A PEGylated dendritic nanoparticulate carrier of fluorouracil. Int J Pharm. 2003;257(1-2):111-124.

23. Jevprasesphant R, Penny J, Jalal R, Attwood D, McKeown NB, D'Emanuele A. The influence of surface modification on the cytotoxicity of PAMAM dendrimers. Int J Pharm. 2003;252(1-2):263-266.

24. El-Sayed M, Ginski M, Rhodes C, Ghandehari H. Transepithelial transport of poly(amidoamine) dendrimers across Caco- 2 cell monolayers. J Control Release. 2002;81(3):355-365.

25. El-Sayed M, Rhodes CA, Ginski M, Ghandehari H. Transport mechanism(s) of poly(amidoamine) dendrimers across Caco-2 cell monolayers. Int J Pharm. 2003;265(1-2):151-157.

26. Kirkpatrick GJ, Plumb JA, Sutcliffe OB, Flint DJ, Wheate NJ. Evaluation of anionic half generation $3.5-6.5$ poly(amidoamine) dendrimers as delivery vehicles for the active component of the anticancer drug cisplatin. J Inorg Biochem. 2011;105(9):1115-1122.

27. Nordenberg J, Panet C, Wasserman L, et al. The anti-proliferative effect of lithium chloride on melanoma cells and its reversion by myo-inositol. Br J Cancer. 1987;55(1):41-46.

28. Kaufmann L, Marinescu G, Nazarenko I, et al. LiCl induces TNF-alpha and FasL production, thereby stimulating apoptosis in cancer cells. Cell Commun Signal. 2011;9:15.

29. Mates JM. Effects of antioxidant enzymes in the molecular control of reactive oxygen species toxicology. Toxicology. 2000;153(1-3):83-104.

30. Wang J, Zhou G, Chen C, et al. Acute toxicity and biodistribution of different sized titanium dioxide particles in mice after oral administration. Toxicol Lett. 2007;168(2):176-185.

31. Brown DM, Donaldson K, Borm PJ, et al. Calcium and ROS-mediated activation of transcription factors and TNF-alpha cytokine gene expression in macrophages exposed to ultrafine particles. Am J Physiol Lung Cell Mol Physiol. 2004;286(2):L344-L353.

32. Lee JH, Cha KE, Kim MS, et al. Nanosized polyamidoamine (PAMAM) dendrimer-induced apoptosis mediated by mitochondrial dysfunction. Toxicol Lett. 2009;190(2):202-207.

33. Naha PC, Davoren M, Lyng FM, Byrne HJ. Reactive oxygen species (ROS) induced cytokine production and cytotoxicity of PAMAM dendrimers in J774 A.1 cells. Toxicol Appl Pharmacol. 2010;246(1-2): 91-99.

34. Mukherjee SP, Lyng FM, Garcia A, Davoren M, Byrne HJ. Mechanistic studies of in vitro cytotoxicity of poly(amidoamine) dendrimers in mammalian cells. Toxicol Appl Pharmacol. 2010;248(3):259-268.

35. Xia T, Kovochich M, Brant J, et al. Comparison of the abilities of ambient and manufactured nanoparticles to induce cellular toxicity according to an oxidative stress paradigm. Nano Lett. 2006;6(8):1794-1807.

36. Xia T, Kovochich M, Liong M, Zink JI, Nel AE. Cationic polystyrene nanosphere toxicity depends on cell-specific endocytic and mitochondrial injury pathways. ACS Nano. 2008;2(1):85-96.

37. Meyskens FL Jr, Buckmeier JA, McNulty SE, Tohidian NB. Activation of nuclear factor-kappa B in human metastatic melanomacells and the effect of oxidative stress. Clin Cancer Res. 1999;5(5):1197-1202.

38. Meyskens FL Jr, Farmer P, Fruehauf JP. Redox regulation in human melanocytes and melanoma. Pigment Cell Res. 2001;14(3):148-154.

39. Farmer PJ, Gidanian S, Shahandeh B, Di Bilio AJ, Tohidian N, Meyskens FL Jr. Melanin as a target for melanoma chemotherapy: pro-oxidant effect of oxygen and metals on melanoma viability. Pigment Cell Res. 2003;16(3):273-279.

40. Snow ET, Sykora P, Durham TR, Klein CB. Arsenic, mode of action at biologically plausible low doses: what are the implications for low dose cancer risk? Toxicol Appl Pharmacol. 2005;207(Suppl 2):557-564.

41. Simon HU, Haj-Yehia A, Levi-Schaffer F. Role of reactive oxygen species (ROS) in apoptosis induction. Apoptosis. 2005;5:415-418. 
International Journal of Nanomedicine

Dovepress

\section{Publish your work in this journal}

The International Journal of Nanomedicine is an international, peerreviewed journal focusing on the application of nanotechnology in diagnostics, therapeutics, and drug delivery systems throughou the biomedical field. This journal is indexed on PubMed Central, MedLine, CAS, SciSearch ${ }^{\circledR}$, Current Contents ${ }^{\circledR} /$ Clinical Medicine,
Journal Citation Reports/Science Edition, EMBase, Scopus and the Elsevier Bibliographic databases. The manuscript management system is completely online and includes a very quick and fair peer-review system, which is all easy to use. Visit http://www.dovepress.com/ testimonials.php to read real quotes from published authors.

Submit your manuscript here: http://www.dovepress.com/international-journal-of-nanomedicine-journal 